\title{
Los Fiscales de la Audiencia de Sevilla en el Siglo XVIII. Notas para su historia
}

\author{
Inmaculada Arias De SaAvedra Alías \\ Universidad de Granada \\ aarias@ugr.es
}

Recibido: 26 de junio de 2009

Aceptado: 19 de mayo de 2010

\begin{abstract}
Resumen
La Audiencia de Sevilla, el tribunal más importante de la Corona de Castilla después de las Chancillerías durante la época moderna, desde su fundación hasta 1790 contó con un solo fiscal y a partir de esta fecha con dos fiscales, uno para asuntos civiles y otro para causas criminales. Este artículo estudia a los magistrados que ocuparon este oficio durante el siglo XVIII y forma parte de un estudio más amplio, actualmente en curso, del tribunal durante esta centuria.
\end{abstract}

Aspectos como los lugares de nacimiento, los años de formación, los estudios universitarios, el disfrute de becas en los colegios mayores, son abordados, junto con las carreras profesionales, las trayectorias antes de acceder al puesto y los ascensos posteriores dentro del cursus honorum administrativo de la época. Se presta especial atención al perfil ilustrado de algunos de ellos, a través de su pertenencia a sociedades y academias, así como del contenido de la producción intelectual de los más relevantes.

Palabras clave: Audiencias, administración, siglo XVIII, Sevilla, fiscales.

\section{Eighteenth century prosecutors of the Royal Audiencia, Seville: notes for their history}

\begin{abstract}
The Royal Audiencia of Seville was the most important law court in the Crown of Castile during the early modern period - second only to the Royal Chancillerías. From its establishment to 1790, the Audiencia was made up of just one prosecutor. It was only in 1790 that two prosecutors were appointed - one for the civil matters and the other one for the criminal causes. This contribution analyzes the magistrates who occupied this office during the eighteenth century, as a part of a broader study on this tribunal during this period, currently under work.
\end{abstract}

The article tackles questions such as place of birth, schooling, universities attended, access to the colegios mayores scholarships and the career pattern - paths which led to the final appointment and promotions within the administrative hierarchy of the period. Particular attention is paid also to the association of several of the magistrates to the Spanish Enlightenment, through membership of learned societies and academies, along with the intellectual output of the more outstanding figures.

Key words: Royal Audiencias, bureaucracy, Spanish Enlightenment, Seville, magistrates. 


\section{Referencia normalizada}

Arias de Saavedra Alías, I. (2011). "Los fiscales de la Real Audiencia de Sevilla en el siglo XVIII. Notas para su historia". Cuadernos de Historia Moderna, Vol 36.: pp. 129-150

Sumario: Introducción. 1. Los fiscales de la Audiencia de Sevilla: naturaleza y formación 2. Colegiales y Manteístas: los inicios de sus carreras 3. Un eslabón en la carrera judicial 4. Nobleza e Ilustración.

\section{Introducción}

La Audiencia de Grados y Alcaldes de Cuadra de la ciudad de Sevilla es, sin lugar a dudas, la Audiencia más importante de la Corona de Castilla, sólo superada en rango y competencias por las Chancillerías. En 1495 los Reyes Católicos organizaron los tribunales ya existentes en la ciudad durante la Edad Media ${ }^{1}$ de modo que a principios del siglo XVI Sevilla contaba con cuatro jueces de grados para conocer en vista y súplica las apelaciones de las causas civiles y cuatro alcaldes de cuadra para las de las causas criminales, procedentes del ámbito del Reino de Sevilla. En 1525 se añadió un quinto juez de grados. Álvarez Jusué, estudioso del tribunal durante esta etapa, considera a Carlos V como el auténtico creador de la Audiencia como tribunal real ${ }^{2}$. El emperador, además de dotarla del personal subalterno necesario, sustituyó a los alcaldes de cuadra -en realidad los alcaldes mayores de la ciudad- por cuatro alcaldes del crimen de nombramiento real. Posteriormente, la real provisión de 5 de mayo de 1554, auténtica partida de nacimiento de la Audiencia, disponía que a partir de este momento adoptara la denominación de Real Audiencia de Sevilla, y que estuviera dirigida por un regente, además de crear el oficio de procurador fiscal ${ }^{3}$.

Un rasgo peculiar de esta Audiencia es que su presidencia estaba reservada a un letrado, a diferencia de otros tribunales castellanos similares, como las Audiencias de Galicia y Canarias ${ }^{4}$, cuya presidencia correspondía a un militar, el capitán general de la región, siendo la figura del regente solo el presidente a efectos judiciales. Otro rasgo peculiar, establecido también por Carlos $\mathrm{V}$, es su fuerte separación respecto del gobierno de la ciudad y de su tierra, lo que hace a este tribunal bastante distinto de otras Audiencias, donde las funciones gubernativas eran muy claras 5 .

${ }^{1}$ Sobre la organización judicial sevillana en la Edad Media véase: ÁLVAREZ JUSUÉ, Aurelio, "Ordenación jurídica y judicial dada a Sevilla por el Santo Rey Fernando de Castilla y León”, Archivo Hispalense, 53,1952, pp. 177-208 y del mismo autor, "La justicia sevillana desde Alfonso XI hasta la Audiencia de Grados", Archivo Hispalense, 60, 1953, pp. 17-50.

2 ÁLVAREZ JUSUÉ, Aurelio, "La Audiencia de Sevilla, creación de Carlos I", Anales de la Universidad Hispalense, 18-19, 1957-58, pp. 67-87.

${ }^{3}$ Ibiden, pp. 82 y 83.

${ }^{4}$ Sobre estos tribunales véase FERNÁNDEZ VEGA, Laura, La Real Audiencia de Galicia, órgano de gobierno durante el Antiguo Régimen (1480-1808), La Coruña, 1983, 3 vols.; LÓPEZ GÓMEZ, Pedro, La Real Audiencia de Galicia y el Archivo del Reino, La Coruña, 1996, 2 vols. y ROSA OLIVERA, L. de la, "La Real Audiencia de Canarias. Notas para su historia", Anuario de Estudios Atlánticos, 3, 1957, pp. 91-161.

${ }^{5}$ CLAVERO, Bartolomé, "Sevilla, concejo y Audiencia". Estudio preliminar de las Ordenanzas de la Real Audiencia de Sevilla, Sevilla, 1995, p. 86. 
Las competencias del tribunal quedaban fijadas en la real provisión de 10 de enero de 1556, conocida como Privilegio de Bruselas. Sus jueces conocerían en grado de apelación todas las causas civiles que se interpusieran ante los alcaldes ordinarios de la ciudad con cuantía superior a diez mil maravedíes, así como las realizadas ante los alcaldes de la Mesta y de Hermandad de la ciudad de Sevilla y su tierra. Ante sus alcaldes de cuadra, que tenían jurisdicción en primera instancia en los casos de corte, se apelaban las causas criminales ${ }^{6}$. Más tarde, en 1566, se concedió al tribunal el conocimiento de los asuntos civiles y criminales de los lugares de señorío y abadengo del reino hispalense, hasta entonces dependientes de la Chancillería de Granada 7

Pese a sus amplias competencias, siempre tuvo la Audiencia de Sevilla una situación de dependencia respecto a la Chancillería de Granada. Al no tener sala de hidalgos, todas las causas de hidalguía que se promovían en el territorio de su jurisdicción habían de resolverse ante el tribunal de Granada. Felipe II amplió la obra del Emperador, agregando a la Audiencia de Sevilla el conocimiento en última instancia de los pleitos civiles de cuantía superior a 300.000 maravedíes, y de los criminales donde pudiera derivarse pena de muerte, mutilación o destierro permanente, procedentes de la Audiencia de Canarias ${ }^{8}$. Quedó así convertida la Audiencia de Sevilla en tribunal supremo de las islas, con una jurisdicción muy amplia, comparable en cierto modo a la de las Chancillerías, aunque no hay que olvidar que no tenía sala de hidalgos, como se acaba de señalar, ni guardaba el sello real, como estos últimos tribunales.

Desde 1572, en que se ampliaron las plazas de ministros de la Audiencia, el tribunal sevillano cantaba con: un regente, ocho jueces de grados, cuatro alcaldes del crimen y un promotor fiscal, además de un contingente importante de personal subalterno: relatores, escribanos, porteros, alguaciles, receptores... 9 . Ésta seguía siendo su plantilla a principios del siglo XVIII. Durante casi toda la centuria tuvo un solo fiscal. A partir de 1790, a consecuencia del problema del bandolerismo que asolaba vastas zonas de Andalucía, se amplió el ámbito territorial de la Audiencia a costa de la Chancillería de Granada ${ }^{10}$. En consonancia con esta ampliación territorial se dispuso la creación de "una plaza de segundo fiscal, con su respectivo agente y las dos de relatores y dos escribanos de cámara"11. A partir de entonces había en la Audiencia de Sevilla un fiscal para asuntos civiles y otro para causas criminales. El más antiguo ejercía la función de fiscal de lo civil, mientras que el recién nombrado lo era como fiscal del crimen.

En este artículo se aborda el estudio de los individuos que desempeñaron el oficio de fiscal de la Audiencia de Sevilla durante el siglo XVIII. Es parte de

\footnotetext{
${ }^{6}$ Novísima Recopilación, lib. V, tít. IV, leyes V, VII y X.

${ }^{7}$ Ibídem, lib. V, tít., IV, ley XLI.

${ }^{8}$ Ibídem, lib. V, tít., IV, ley XI.

${ }^{9}$ MORALES PADRÓN, Francisco, Historia de Sevilla. La ciudad del Quinientos, Sevilla, 1977, p. 227.

${ }^{10}$ Novísima Recopilación, libro V, tít. IV, ley XLII. Un mapa del territorio jurisdiccional de la Audiencia en GARRIGÓS PICÓ, Eduardo; "Organización territorial a fines del Antiguo Régimen", en ARTOLA, Miguel, La economía española a finales del Antiguo Régimen. IV: Las Manufacturas, Madrid, Alianza, 1982, p. 93.

${ }^{11}$ Archivo Histórico Nacional [AHN], Consejos, legs. 13.502-13.503.
} 
una investigación más amplia acerca de los ministros de ese tribunal a lo largo de esta centuria.

\section{Los Fiscales de la Audiencia de Sevilla: naturaleza y formación}

La figura del fiscal era muy importante dentro del organigrama de ministros de la Audiencia. En el Antiguo Régimen su función era bastante distinta a la ejercida por el ministerio fiscal en la actualidad. Desde la Edad Media el fiscal era considerado el representante de los intereses económicos de la Corona por lo que, en un principio, sólo intervenía para defender los intereses del fisco, en las causas en las que se esperaban penas pecuniarias, es decir en las que había repercusiones para la cámara del rey y generalmente previa denuncia de un particular ${ }^{12}$. Con el tiempo, aunque se mantendría como esencial de la función de los fiscalesladefensadelpatrimonioydelajurisdicciónreal ${ }^{13}$, fueevolucionandoarepresentante de la acción pública derivada del delito, por lo que pasaron a intervenir en todos los procesos ${ }^{14}$. Los Reyes Católicos establecieron su obligación de intervenir de oficio en las causas criminales que llegaran a las Audiencias ${ }^{15}$. En 1503 se les obliga también a perseguir de oficio a los oficiales de las Audiencias que contravinieran algúnaspecto de las ordenanzas del tribunal ${ }^{16}$. Desde principios del siglo XVI debían llevar un libro donde recogieran todas las causas en las que estaban interviniendo ${ }^{17}$. Más tarde Felipe III estableció en 1606 la obligación de los fiscales de informar semanalmente a sus tribunales respectivos sobre el estado de los pleitos que estaban siguiendo ${ }^{18}$.

A pesar de que Felipe II estableció que en las Audiencias hubiera dos fiscales, uno para las causas civiles y otro para las criminales ${ }^{19}$, en la Audiencia de Sevilla hasta 1790 solo hubo un fiscal. En la Real Cédula promulgada en Madrid el 14 de mayo de 1566, donde se fijaban con detalle las competencias de la Audiencia de Sevilla y de sus ministros, entre otras cuestiones se dispuso el establecimiento de un fiscal: "ordenamos y mandamos que de aquí adelante en essa Audiencia aya fiscal que asista en nuestro nombre a las dichas causas eclesiásticas y de coronados y a las otras que tocaren al nuestro patrimonio y corona, el qual nos mandaremos luego nombrar y señalar, para que esté y resida en essa Audiencia y asista a las dichas causas"20. El Real Acuerdo de la Audiencia, es decir el regente, jueces y alcaldes de ella, recibían y tomaban juramento al fiscal en el inicio del desempeño del

\footnotetext{
${ }^{12}$ Esta función primordial está definida en Novisima Recopilación, lib. V, tít. XVII, ley III.

${ }^{13}$ Carlos V por ley de 4 de diciembre de 1528 les recuerda la obligación de activar el despacho y fenecimiento de las causas de las que se derivan derechos para la Cámara (Ibid., ley VII).

${ }^{14} \mathrm{La}$ evolución de la figura del fiscal en CORONAS GONZÁLEZ, Santos M. ${ }^{\mathrm{a}}$, Ilustración y derecho. Los fiscales del Consejo de Castilla en el siglo XVIII, Madrid, Ministerio de Administraciones Públicas, 1992, pp.37-41.

${ }^{15}$ Novísima Recopilación., lib. V, tít. XVII, ley IV.

${ }^{16}$ Ibidem, ley VIII.

${ }^{17}$ Ibídem, ley IX.

${ }^{18}$ Ibidem, ley XI.

${ }^{19}$ Novísima Recopilación, lib. V, tít. XVII, ley I.

${ }^{20}$ Ordenanzas de la Real Audiencia de Sevilla, Sevilla, Universidad de Sevilla, 1995 (ed. facsímil), libro III, Título II, ley XLIII.
} 
cargo $^{21}$. De acuerdo con su posición en orden de importancia en el tribunal, su lugar de asiento era después del alcalde del crimen más reciente y antes del alguacil mayor ${ }^{22}$, pero se le reconocían los honores propios de los ministros de la Audiencia ${ }^{23}$. Del mismo modo que el regente, oidores y alcaldes, tenía prohibido contraer matrimonio en la ciudad de Sevilla o en el distrito de la Audiencia sin permiso real, para evitar familiaridades con quienes estaban bajo su jurisdicción ${ }^{24}$.

Desde principios del siglo XVIII y hasta 1808 desempeñaron el oficio de fiscal de la Audiencia de Sevilla 25 magistrados. El primero de ellos, Jerónimo Pesio y Mendoza, había sido nombrado en 1699 por Carlos II, el resto lo serían con posterioridad a 1700. Conocemos muchos aspectos de las carreras de estos magistrados, aunque no con tanto detalle como en el caso de los regentes ${ }^{25}$. Sobre los fiscales la información es desigual y varía de algunos casos en que es muy completa, a otros en que apenas conocemos que desempeñaron el oficio en Sevilla y poco más ${ }^{26}$.

Desde comienzos de la época moderna se estableció como norma general en los tribunales castellanos que la titularidad de sus plazas togadas estuviera vedada a los jueces nacidos en el ámbito geográfico de estos tribunales. En realidad esta política comenzó a aplicarse desde los Reyes Católicos, pero fue Felipe II quien la sancionó como ley, en virtud de la Real Provisión de 6 de enero de $1588^{27}$. En el caso de la Audiencia de Sevilla esta prohibición estaba vigente incluso con anterioridad, concretamente desde $1556^{28}$. La política de exclusión de los naturales se mantuvo en líneas generales en

${ }^{21}$ Ibídem, lib. I, título V, ley I.

${ }^{22}$ Ibidem, leyes 3 y 4.

${ }^{23}$ Por ejemplo, usaban cojines de terciopelo para arrodillarse, como los oidores y alcaldes en las misas celebradas en el tribunal (Ibid., ley 5).

${ }^{24}$ Real Cédula de Sevilla, 16 de mayor de 1560 (Ibid., lib. I, tít. II, ley VII).

${ }^{25}$ Sobre las carreras de estos últimos véanse ARIAS DE SAAVEDRA ALÍAS, Inmaculada: "Formación universitaria y promoción en la carrera administrativa en magistrados de la Audiencia de Sevilla en el siglo XVIII", en Derecho, Historia, Universidades. Estudios dedicados a Mariano Peset, Valencia, Universitat de València, 2007, vol. I, pp. 143-153 y "Algunas notas sobre los regentes de la Audiencia de Sevilla en el siglo XVIII", en Homenaje a D. Antonio Domínguez Ortiz, Granada, Universidad de Granada-Junta de Andalucía, 2008, vol. III, pp. 111-133.

${ }^{26} \mathrm{La}$ información sobre estas carreras está sacada de la documentación procedente de AHN: Personal de la Audiencia de Sevilla, Consejos, legs. 13.501 a 13.503; Relaciones de méritos: Consejos, legs. 13.348 a 13.386 y libros de plazas, L. 732 a 740, así como la del Archivo General de Simancas [AGS], provisiones de plazas: Gracia y Justicia, legs. 133 a 165. Se ha utilizado también la abundante bibliografía sobre historia de la administración de la época, así como de la base de datos Ozanam que mantiene el profesor Dedieu. Una descripción de la base de datos en DEDIEU, Jean Pierre, "Un instrumento para la historia social: la base de datos Ozanam", Cuadernos de Historia Moderna, núm. 24 (2000), pp. 11-31. También he utilizado, con resultado dispar, el ABEPI (Archivo biográfico de España, Portugal e Iberoamérica), Munich, Kgsaur, 1985 en adelante (ed. en microfichas).

27 "Hase de excusar buenamente, quanto se pudiere, que para la Chancillería de Valladolid no se me propongan los naturales de aquel distrito, ni para la de Granada del suyo, sino por el contrario; y lo mismo se guardará en lo que toca a las Audiencias de Galicia y Sevilla, y a los corregidores y otros oficios de justicia" Novísima Recopilación, lib. IV, tít. IV, ley I.

28 "Y porque en los dichos regentes y Jueces de Grados haya entera libertad: mandamos que ninguno dellos sean naturales de la dicha ciudad de Sevilla ni de su tierra, ni de la villa de Carmona ni de su tierra; y que si fueren nombrados que no sean rescebidos sin nuestro expresso mandato, en que no entendemos dispensar “ (Bruselas, 10 de enero de 1556, Novísima Recopilación, lib. V, tít. IV, ley I). 
los siglos siguientes, especialmente en lo que se refiere a las plazas de regentes y fiscales, pero también entre oidores y alcaldes del crimen. Por lo general las plazas togadas de Audiencias y Chancillerías solían ser proveídas en magistrados foráneos al ámbito jurisdiccional de los tribunales. Sin embargo, el tribunal sevillano fue en este aspecto bastante atípico, pues contó con un porcentaje de jueces sevillanos muy significativo. Esta circunstancia se debió a que, por mantener privilegios de los tribunales medievales de la ciudad, con carácter excepcional en este tribunal no había incompatibilidad con los naturales en el oficio de alcalde del crimen. Como durante la Edad Moderna se produjo con frecuencia la promoción de los alcaldes de cuadra a jueces de grados, por este sistema un grupo significativo de naturales del ámbito jurisdiccional del tribunal terminaron siendo jueces civiles del mismo. Así la Audiencia de Sevilla se sitúa en una situación intermedia entre los tribunales castellanos, donde la presencia de jueces naturales es excepcional, y los tribunales de la Corona de Aragón donde, como es bien sabido, los jueces naturales eran exclusivos durante la época foral y siguieron manteniendo ciertas plazas incluso durante el siglo XVIII para asegurar una mejor aplicación de los aspectos del derecho foral que pervivieron a la Nueva Planta ${ }^{29}$.

Durante el siglo XVIII la Audiencia de Sevilla no sólo tuvo bastantes oidores y alcaldes del crimen nacidos en Sevilla y su reino, sino que también hubo excepcionalmente regentes y fiscales naturales de su ámbito jurisdiccional. En el caso de los primeros, algunos habían nacido en la propia Sevilla, otros en su ámbito de la Audiencia ${ }^{30}$. En cuanto a los fiscales, entre los 18 cuyo lugar de nacimiento conocemos $^{31}$, también hay uno que contraviene la norma de ser foráneo, Juan Francisco Lerín de Bracamonte. Aunque es nacido en Écija, sus padres estaban avecindados en Sevilla, y pertenecían a una conocida familia local ${ }^{32}$. En la ciudad del Betis transcurrieron sus años de formación, estudió en su universidad, gozando de una beca del Colegio de Santa María de Jesús, anejo a la misma ${ }^{33}$.

El resto de los fiscales eran foráneos y procedían de distintos lugares de nuestro país. José García León Pizarro era andaluz, natural de Motril. Cosme García Talón era natural de Murcia. Extremeños eran Juan Cáceres Laso de la Vega, que había

${ }^{29}$ La cuestión de las plazas de naturales en los tribunales de la Corona de Aragón en MOLAS RIBALTA, Pere, "Las Audiencias borbónicas en la Corona de Aragón”, en Historia social de la administración española. Estudios sobre los siglos XVII y XVIII, Barcelona, 1980, pp. 126-134.

${ }^{30}$ Los regentes Pedro Ursúa Arizmendi, conde de Gerena (1698-1706) y Francisco Díaz Bermudo (1806-1813) eran sevillanos. Manuel Torres y Rico (1713-1732) era natural de Ayamonte y Joaquín Antonio Bazán Melo, marqués de San Gil, su sucesor en la regencia (1733-1734) no se sabe con seguridad si nació en Sevilla o en Jerez de los Caballeros, pero en cualquier caso dentro del ámbito jurisdiccional de la Audiencia.

${ }^{31}$ Desconozco el lugar de nacimiento de los fiscales: Pesio Mendoza, Román Meléndez, Pérez Vivar, Roa Lucas, Fernández Soler, Navarro Pingarrón y Miguel Gómez García.

32 Justino Matute y Gaviria lo sitúa entre los sevillanos ilustres y dice de él "a quien debemos contar entre los sevillanos por estar en esta ciudad avecindados sus padres y dándole en ella educación y carrera, nació casualmente en Écija" (Hijos de Sevilla señalados en Santidad, Letras, Armas, Artes o Dignidad por..., Sevilla, en la oficina de El Orden, 1887, tomo II).

${ }^{33}$ Así lo acredita su expediente de limpieza de sangre para obtener una beca colegial en Archivo Histórico de la Universidad de Sevilla [AHUSE], S 030, fols. 97-181. 
nacido en Hornachos (Badajoz) y Juan Pablo Forner, natural de Mérida (Badajoz), aunque este último era de una familia de origen valenciano ${ }^{34}$. Joaquín José Márquez Villalobos era natural de Talavera (Toledo). Otro grupo eran aragoneses: Tomás Martínez Galindo, natural de Borja (Zaragoza), Felipe Codallos, nacido en Tamarite de Litera (Huesca) y Nicolás María Sierra, natural de Zaragoza. De la diócesis de La Calahorra eran Juan Manuel Cereceda y José Ruiz Ubago Busto, nacidos en Santa Cruz de Yanguas y El Ciego, respectivamente. De la diócesis de Burgos era José Portilla Bustamante, natural de Vejorís, en el valle de Toranzo (Cantabria). Castellano-leoneses eran Francisco Rodríguez Castañón, natural de Lois (León), Pedro Contreras Zúñiga, natural de Segovia y Juan Miranda y Oquendo, de Ciudad Rodrigo. José Hevia Noriega era asturiano, nacido en Oviedo, Juan Francisco Cuadra Hernández era vasco, de Somorrostro y Francisco Leoz Echalaz, navarro, de Pamplona.

Todos ellos habían realizado estudios de Derecho -canónico o civil, o en algunos casos de ambos derechos- en distintas universidades del reino. El grupo más nutrido lo hizo en las tres universidades mayores del reino. En la Universidad de Salamanca se habían formado Francisco Leoz Echalaz -bachiller en cánones y licenciado en leyes-, Juan Miranda y Oquendo -doctor en leyes- y Nicolás María Sierra -doctor en leyes-. En Valladolid habían realizado sus estudios Juan Manuel Cereceda y José Ruiz Ubago Busto. Algunos comenzaron sus estudios en un centro y los completaron en otro, realizando la peregrinatio academica tan característica de los estudiantes universitarios en esta etapa. Así Pedro Contreras Zúñiga comenzó sus estudios de leyes en Alcalá, estudió cánones en Salamanca y obtuvo el grado de licenciado en la Universidad de Ávila ${ }^{35}$ y Alonso Rodríguez Castañón comenzó sus estudios en la Universidad de Oviedo, pero se graduó de bachiller en leyes en la Universidad de Valladolid y de bachiller en cánones en Salamanca, licenciado en leyes por la Universidad de Ávila, se incorporó más tarde a la de Alcalá ${ }^{36}$. Pedro Contreras Zúñiga estudio Leyes en Salamanca y Cánones en Alcalá; Juan Francisco Cuadra Hernández estudió Leyes en Valladolid y se doctoró en Cánones en Alcalá y Juan Pablo Forner realizó sus estudios de Artes y Derecho civil y canónico en Salamanca, pero obtuvo el título de bachiller en Alcalá. Otros estudiaron en universidades regionales cercanas al lugar de residencia familiar: Tomás Martínez Galindo lo hizo en la Universidad de Zaragoza, Francisco Lerín de Bracamonte se doctoró en leyes en la Universidad de Sevilla $^{37}$, como ya se ha señalado, Felipe Codallos lo hizo en la de Huesca y José García León Pizarro, que también accedió al grado de doctor, lo hizo en la de Granada. De otros fiscales desconocemos la información relativa a sus estudios.

\footnotetext{
${ }^{34}$ Sobre sus orígenes familiares véase LÓPEZ, François, Juan Pablo Forner y la crisis de la conciencia española del siglo XVIII, Salamanca, Junta de Castilla y León, 1999, pp. 22 y ss.

${ }^{35}$ Burkholder, Mark A., Biographical Dictionary of Councilors of the Indies, 1717-1808, New York, Greenwood Press, 1984, p. 31.

${ }^{36}$ Relación de méritos en AHN, Consejos, leg. 13.386, exp. 234.

${ }^{37}$ Doctorarse siendo colegial no era muy habitual, pues los colegiales solían acceder a cátedras sin necesidad de hacerlo (Cf. AGUILAR PIÑAL, Francisco, La Universidad de Sevilla en el siglo XVIII. Estudio sobre la primera reforma universitaria moderna, Sevilla, Publicaciones Universidad, 1969, p. 111).
} 


\section{Colegiales y Manteístas. Los inicios de sus carreras}

Durante el siglo XVIII la mayoría de los nombrados para ocupar plazas de fiscales en la Audiencia de Sevilla eran manteístas. No obstante, a lo largo del siglo se nombró un significativo grupo, nueve concretamente, que durante su etapa de formación habían ocupadouna de las minoritarias plazas de becarios de los prestigiosos Colegios Mayores del reino. Sin duda, su condición de becarios les ayudó en su promoción profesional.

Tres de estos fiscales habían sido becarios en el colegio salmantino de San Bartolomé: Francisco Leoz Echalaz, Joaquín José Márquez Villalobos y Nicolás María Sierra ${ }^{38}$. Le seguían, con dos fiscales cada uno, los colegios de San Ildefonso de Alcalá y Santa Cruz de Valladolid. Habían disfrutado becas del centro alcalaíno Alonso Rodríguez Castañón y Juan Francisco Cuadra Hernández ${ }^{39}$, mientras que las obtuvieron del vallisoletano Juan Manuel Cereceda y José Ruiz Ubago Busto ${ }^{40}$. Por su parte, Pedro Contreras Zúñiga, disfrutó una beca del colegio salmantino del Arzobispo $^{41}$. Por último Juan Francisco Lerín de Bracamonte se formó en el colegio sevillano de Santa María de Jesús ${ }^{42}$, centro con categoría de colegio mayor ${ }^{43}$, pero con menor proyección profesional que los seis grandes colegios mayores.

El nombramiento de fiscales colegiales se concentra mayoritariamente en el reinado de Felipe V. Los dos primeros regentes que ejercieron durante el reinado del fundador de la dinastía borbónica -Jerónimo Pesio Mendoza y Tomás Martínez Galindo- eran manteístas y desenvolvieron su actividad en un contexto de promoción general de

${ }^{38}$ Sobre los colegios salmantinos véase CARABIAS TORRES, Ana, Colegios mayores centros de poder. Los colegios mayores de Salamanca durante el siglo XVI, Salamanca, Universidad, 1986. Los colegiales de San Bartolomé en esta etapa en ROXAS Y CONTRERAS, marqués de Alventos, José, Historia del Colegio de San Bartolomé de Salamanca, Mayor de la célebre Universidad de Salamanca. Vida del Excmo. y Rvdmo. Don Diego de Anaya y Maldonado, arzobispo de Sevilla, su fundador, y noticia de sus ilustres hijos, Madrid, Andrés Ortega, 1766-1770, 3 vols. y CARABIAS TORRES, Ana M.", "Catálogo de Colegiales del Colegio Mayor de San Bartolomé (1700-1840)", Studia Historica. Historia Moderna, IX, 1991, pp. 43-88. Leoz Echalaz: p. 50 y Sierra p. 71.

${ }^{39}$ Una síntesis sobre el mismo en GONZÁLEZ NAVARRO, Ramón, "El Colegio Mayor de San Ildefonso y la Universidad de Alcalá", en DELGADO CRIADO, Buenaventura. (coord.), Historia de la educación en España y América, Madrid, 1993, pp. 258-279. El catálogo de sus colegiales en GUTIÉRREZ TORRECILLA, Luis Miguel, Catálogo biográfico de colegiales y capellanes del Colegio Mayor de San Ildefonso de Alcalá (1508-1786), Alcalá de Henares, 1992. Rodríguez Castañón p. 90 y Cuadra Hernández p. 31.

${ }^{40}$ Sobre el mismo véase: SOBALER SECO, M. a Ángeles, Los colegiales de Santa Cruz. Una élite de poder, 1484-1670, Valladolid, 1987 y de la misma autora, Catálogo de colegiales del Colegio Mayor de Santa Cruz de Valladolid (1484-1786), Valladolid, 2000. Cereceda p. 318 y Ruiz Ubago p. 324.

${ }^{41}$ La nómina de sus colegiales en FERRER EZQUERRA, Luis y MISOL GARCÍA, Higinio, Catálogo de Colegiales del Colegio Mayor de Santiago de Cebedeo, Salamanca, 1956. Contreras Zúñiga en p. 105.

${ }^{42}$ Sobre este centro, unido estrechamente a la Universidad de Sevilla, véase: AGUILAR PIÑAL, Francisco, op.cit., especialmente pp. 28-37 y 53-87. Relación de colegiales durante el siglo XVIII en Apéndice I, pp. 515-517 y OLLERO PINA, José Antonio, La Universidad de Sevilla en los siglos XVI y XVII, Sevilla, 1993. Sobre el fundador del colegio y su obra, véase GIL, Juan, "Maese Rodrigo Fernández de Santaella. Vida y obra” en SERRERA, Ramón M. y SÁNCHEZ MANTERO, Rafael, V Centenario. La Universidad de Sevilla, 1505-2005, Sevilla, 2005, pp. 41-59.

${ }^{43}$ La categoría de Colegio Mayor le había sido reconocida por Felipe IV en 1623 y fue refrendada por Felipe V en 1716 y 1716. (AGUILAR PIÑAL, F., op. cit., p. 85). 
los manteístas que tuvo lugar en los primeros años del reinado, sobre todo durante el mandato del también manteísta Melchor de Macanaz. Tras la caída del poderoso fiscal del Consejo de Castilla, los colegiales se vieron promocionados en todos los puestos de la administración, así los tres siguientes nombramientos de fiscales en la Audiencia de Sevilla fueron de colegiales: Pedro Domingo Contreras Zúñiga, Francisco Leoz Echalaz y Alonso Rodríguez Castañón. Los dos siguientes nombramientos se harían a manteístas -Francisco Román Meléndez y Juan Pérez Vivar- y durante el resto del reinado de Felipe V alternarían los colegiales -Juan Francisco Lerín de Bracamonte y Juan Francisco Cuadra Hernández- con los manteístas -Juan Miranda y Oquendo y Felipe Codallos-. De los dos fiscales nombrados en el reinado de Fernando VI uno sería manteísta -José Portilla Bustamante- y otro colegial -Juan Manuel Cereceda-. La proporción de nombramientos de fiscales colegiales descendió significativamente a partir del reinado de Carlos III que, como es bien sabido, emprendió la reforma de los colegios $^{44}$ y abatió el poder de los colegiales promocionando a los manteístas. Durante el mismo, de los tres nombramientos de fiscales realizados, sólo uno recayó en un colegial -José Ruiz Ubago Busto-. El proceso continuó durante el reinado de Carlos IV, de los ocho fiscales nombrados durante este periodo, sólo dos eran colegiales -Joaquín José Márquez Villalobos y Nicolás M. ${ }^{a}$ Sierra. Pero hay que tener en cuenta que estos dos últimos no pueden ser asimilados totalmente a los colegiales anteriores, pues accedieron a una beca en el Colegio salmantino de San Bartolomé, de acuerdo con el decreto de la reforma de los colegios que ya había tenido lugar ${ }^{45}$.

En general las carreras de estos colegiales se desenvolvieron de forma rápida y brillante. Fue muy frecuente que las empezaran con el desempeño de cátedras, algunas veces en sustitución, pero en la mayoría de los casos en propiedad, coincidiendo con sus largas etapas de estancia en los colegios mayores. Durante estos años iban cambiando de unas cátedras a otras, ascendiendo a las de más importancia y dotación. Sobre estas actividades suelen dar abundantes noticias las relaciones de ejercicios y méritos conservadas, la mayoría de ellas redactadas e impresas en los inicios de sus carreras en la administración. En ellas se presta atención al elevado número de años de estudio realizado, a los ejercicios de conclusiones en que participaban y al desempeño de cátedras. Como es bien sabido, en aquella época el destino docente universitario no era considerado siempre como un fin en sí mismo. Con frecuencia era más bien un destino cómodo a la espera de la oferta de un puesto más lucrativo en la administración real o eclesiástica. La espera a veces se dilataba en el tiempo y los colegiales permanecían como huéspedes en los centros, al tiempo que desempeñaban cátedras, mientras aguardaban un destino de su agrado, desvirtuando el sentido y orientación inicial de estas fundaciones.

${ }^{44}$ Sobre esta cuestión véase: SALA BALUST, Luis, Visitas y reformas de los Colegios Mayores de Salamanca en el reinado de Carlos III, Valladolid, 1958, así como los escritos de PÉREZ BAYER, Francisco, Por la libertad de la literatura española. Estudio preliminar de A. Mestre, Alicante, 1991 y Diario histórico de la reforma de los seis colegios mayores de Salamanca, Valladolid y Alcalá. Edición y estudio preliminar de A. Mestre Sanchís, J. A. Catalá Sanz y P. Pérez García, Valencia, 2002.

${ }^{45}$ CARABIAS TORRES, A., art. cit., p. 75. 
Así, Pedro Domingo Contreras Zúñiga, colegial del Arzobispo, permaneció durante 18 años en la Universidad, desempeñando cátedras de Instituta, Código y Digesto viejo $^{46}$. Francisco Leoz Echalaz, colegial de San Bartolomé, fue sucesivamente catedrático de Clementinas, Decretales mayores y Visperas de Cánones ${ }^{47}$. Alonso Rodríguez Castañón, colegial jurista de San Ildefonso de Alcalá, fue sucesivamente catedrático de Instituta I y II, Decretales menores, Decreto y Vísperas de cánones, durante una larga etapa de 16 años $^{48}$, permitiéndose rechazar algún puesto importante, como el de fiscal de la Audiencia de Lima ${ }^{49}$, hasta conseguir un puesto de su agrado, el de fiscal de la Audiencia de Sevilla. Juan Francisco Lerín de Bracamonte, doctor en Derecho canónico por la Universidad de Sevilla, obtuvo por oposición la cátedra de Código y solo tres meses más tarde ascendió a la de Decreto. Cuando ocupaba el rectorado de la Universidad, coincidió con la estancia de Felipe V y su corte en Sevilla, por lo que presidió la delegación de la Universidad que acogió al rey en su visita al centro educativo. Su intervención en este acto, muy del agrado del monarca, le valió el nombramiento como fiscal en la Audiencia ${ }^{50}$. Juan Manuel Cereceda, colegial de Santa Cruz, ocupó las cátedras de Instituta antigua, Código antigua, Digesto Viejo y Sexto en la Universidad de Valladolid. Ocupaba esta última cuando fue nombrado fiscal de la Audiencia sevillana ${ }^{51}$. Su sucesor en la fiscalía, José Ruiz de Ubago Busto, que había coincidido con él en el mismo colegio, fue catedrático de Decretales y Código antiguo en la universidad vallisoletana, abandonando la cátedra al obtener su primer destino en la administración, el de Juez Mayor de Vizcaya, en la Chancillería de Valladolid, un puesto desde el que accedería a la fiscalía sevillana. No parece que los dos últimos colegiales mayores que fueron nombrados fiscales en fechas tardías - José Márquez Villalobos y Nicolás M. ${ }^{a}$ Sierra Rubio- fueran catedráticos antes y es que a esas alturas del siglo se habían realizado las reformas en las universidades del reino y la función de catedrático de universidad se había profesionalizado más.

Si había sido, por el contrario, catedrático uno de los manteístas que accedieron a fiscales en el reinado de Felipe V, Felipe Codallos. Formado en la universidad de su tierra natal, Huesca, donde se graduó de doctor, obtuvo una cátedra de leyes que desempeñó, hasta abandonarla para ocupar la plaza de fiscal de la Audiencia de Sevilla. Otros fiscales manteístas habían optado a cátedras en numeras ocasiones sin conseguir las plazas. No obstante aducían en sus relaciones de méritos el haber opositado, a pesar de los reiterados fracasos. Así el fiscal Juan de Miranda y Oquendo expone en su currículo veintitrés años de estudios mayores de jurisprudencia en la Universidad de Salamanca, de los cuales son "diez y seis años de oposición, rigurosa

\footnotetext{
${ }^{46}$ FERRER EZQUERRA, L. y MISOL GARCÍA, H., op. cit., p. 105.

${ }^{47}$ CARABIAS TORRES, A., art. cit., p. 50.

${ }^{48}$ GUTIÉRREZ TORRECILLA, Luis Miguel y BALLESTEROS TORRES, Pedro, Cátedras y catedráticos de la Universidad de Alcalá en el siglo XVIII, Alcalá de Henares, 1998, pp. 157-178.

${ }^{49}$ Una síntesis biográfica del mismo en BURKHOLDER, Mark A. and CHANDLER, D.S., Biographical Dictionary of Audiencia Ministers in the Americas, 1687-1821, Westport, Greenwoood Press, 1982, p. 295.

${ }^{50}$ MATUTE Y GAVIRIA, J., op. cit., II, p.

${ }^{51}$ SOBALER SECO, M. A., Catálogo..., p. 318.
} 
y sin intermisión". Durante este tiempo realizó numerosos actos de conclusiones, sustituciones en diversas cátedras, actuó como examinador y desempeñó en la Universidad los oficios de contador, diputado, bibliotecario y asesor del Canciller ${ }^{52}$. Todo un largo camino hasta obtener el nombramiento de fiscal. Por su parte José Portilla Bustamante realizó 24 años de estudios superiores en la Universidad de Valladolid durante los cuales, además de graduarse de bachiller en leyes y cánones, realizó 16 oposiciones fallidas a cátedras. En estos años impartió cursos extraordinarios, realizó actos de conclusiones y presidió actos académicos varios, además de actuar como pasante en derecho. Obtuvo el nombramiento de fiscal de la Audiencia de Sevilla tras aducir los méritos de su tío, Fray Francisco de la Portilla, obispo de Mallorca y partidario de la causa borbónica, quien, a causa de su posicionamiento político, había sufrido cárcel durante la Guerra de Sucesión y de otro tío, Antonio de la Portilla Barreda, relator de la Cámara de Castilla ${ }^{53}$.

\section{Un eslabón en la carrera judicial}

Para la mayoría de los magistrados objeto de nuestro estudio -concretamente para 17 de un total de 25- el oficio de fiscal de la Audiencia de Sevilla fue el primer puesto que desempeñaron en la administración. Así ocurrió con todos los catedráticos a los que acabo de referirme-Pedro Domingo Contreras Zúñiga, Francisco Leoz Echalaz, Alonso Rodríguez Castañón, Juan Francisco Lerín de Bracamonte, Juan Miranda y Oquendo, Felipe Codallos, Juan Manuel Cereceda y José Ruiz Ubago Busto-, que pasaron de la cátedra a la fiscalía, sin solución de continuidad. Del mismo modo, algunos colegiales pasaron del colegio a la fiscalía, como ocurrió con Juan Francisco Cuadra Hernández, Joaquín José Márquez Villalobos-que era rector del colegio salmantino deSan Bartolomé en el momento de ser nombrado- o Nicolás María Sierra. En otros casos, tratándose también de un primer destino, accedían a él desde otras ocupaciones. Tomás Martínez Galindo, eran un abogado de ideario filipista que desempeñaba la abogacía en Zaragoza cuando fue nombrado en 1707 fiscal de la Audiencia de Sevilla ${ }^{54}$. También accedió al puesto desde el desempeño de la abogacía el ovetense José Hevia Noriega.

Otros accedieron a la fiscalía sevillana desde otros puestos de menos rango de la administración de justicia. Algunos lo hicieron desde corregimientos. Es el caso de José Pérez Vivar, que era corregidor de Huete en el momento de ser nombrado ${ }^{55}$, o

\footnotetext{
${ }^{52}$ Relación de méritos en AHN, Consejos, legs. 13.361-62, exp. 2.

${ }^{53}$ Relación de méritos en AGS, Gracia y Justicia, leg. 146. Ficha biográfica en PÉREZ SAMPER, M. ángeles, "Jueces y abogados en la Sevilla de mediados del siglo XVIII. Apuntes para un estudio sociológico" en Estudios de economía e historia, Málaga, 1981, p. 60.

${ }^{54}$ LATASSA Y ORTÍN, Félix de, Biblioteca nueva de los escritores aragoneses que florecieron desde el año de 1689 hasta el de 1753, Pamplona, en la oficina de Joaquín de Domingo, 1800, tomo IV.

${ }^{55}$ Había sido corregidor de Huete desde agosto de 1718 a noviembre del año siguiente en que ascendió a la fiscalía (A.H.N., Consejos, lib. 711, f. 276). El corregimiento de Huete era un corregimiento "de letras", que con las reformas de Carlos III sería considerado de segunda categoría (GONZÁLEZ ALONSO, Benjamín, El corregidor castellano (1348-1808), Madrid, 1970, pp. 280 y 285).
} 
de José García León y Pizarro y Ramón Navarro Pingarrón, que procedían ambos del corregimiento de Baeza ${ }^{56}$. José Antonio Fernández Soler accedió a la fiscalía desde el puesto de alcalde mayor subalterno y teniente segundo del asistente de Sevilla. Por último, hay dos casos de procedencia de otras audiencias. El murciano Cosme García Talón, había sido alcalde mayor y abogado del concejo de su ciudad, nombrado fiscal del crimen de la Audiencia de Valencia, no llegaría a ocupar el puesto, pues pronto pasó a la Sala de Alcaldes de Casa y Corte de Madrid, primero como fiscal y después como alcalde. Tras la caída de su paisano Macanaz, la reforma del tribunal madrileño fue la causa de su nombramiento como fiscal en la Audiencia de Sevilla, nombramiento que no parece ser propiamente un ascenso, sino más bien al contrario ${ }^{57}$. Tampoco parecía serlo el de Francisco Román Meléndez, que procedía de la Audiencia de Canarias, donde había permanecido durante catorce años, desempeñando los oficios de fiscal y de juez. Por venirse a la península y concretamente a un tribunal tan prestigioso como el de Sevilla, estuvo dispuesto a volver al oficio de fiscal y, a pesar de alegar su antigüedad, tuvo que estar cuatro años en la fiscalía, antes de acceder a una plaza de juez de grados del mismo tribunal ${ }^{58}$. No faltan tampoco ejemplos como el de Forner en que el oficio de fiscal se daba a un manteísta que no había desempeñado función alguna en la administración. En su caso, los servicios prestados al país con la redacción de su Oración apologética por la España y su mérito literario (1786), en defensa de la aportación española a la ciencia europea y la consiguiente protección de Floridablanca le sirvieron para obtener este nombramiento.

No conocemos la edad con la que accedieron al cargo todos los fiscales de la Audiencia de Sevilla, sino sólo en 16 de los $\operatorname{casos}^{59}$. La edad media de acceso al cargo es de 39 años, pero se trata sólo de una cifra media, poco representativa, porque los distintos fiscales tenían edades muy variadas en el momento de ser nombrados. El más joven de todos es Francisco Leoz Echalaz, que consigue el nombramiento de fiscal con sólo treinta años. Pero hubo otros también bastante jóvenes: treinta y un años tenían Cosme García Talón y Felipe Codallos en el momento de ser nombrados, y treinta y cuatro Juan Miranda y Oquendo, Juan Pablo Forner y José Hevia Noriega. Otros sobrepasaban con creces los cuarenta e incluso los cincuenta años. Alonso Rodríguez Castañón fue el que recibió el nombramiento con más edad, 54 años. Pero eran también bastante mayores José Portilla Bustamante y Juan Cáceres Laso de la Vega, ambos habían cumplido 48 años.

${ }^{56}$ El corregimiento de Baeza y Úbeda era en los inicios del siglo XVIII un corregimiento "de capa y espada" que en 1768 se transformó en corregimiento "de letras". Según las disposiciones de 1783 sería considerado corregimiento "de término", es decir, de tercera categoría, la más alta (Ibid., pp. 280, 284 y 285.

${ }^{57}$ MOLAS RIBALTA, Pere, La Audiencia borbónica del Reino de Valencia (1707-1834), Universidad de Alicante, 1999, p. 30.

${ }^{58} \mathrm{AHN}$, Consejos, libs. 535 y 735.

${ }^{59}$ Ignoramos el año de nacimiento de J. Pesio, F. Román Meléndez, Juan Pérez Vivar, Juan Francisco Cuadra Hernández, J. J. Márquez Villalobos, José Roa Lucas, Juan Antonio Fernández Soler y Miguel Gómez García. 
La mayoría de los fiscales de la Audiencia de Sevilla permanecieron varios años en este cargo. La media de permanencia en él es de algo más de cuatro años, pero la duración de las distintas fiscalías es muy variada. El que estuvo más tiempo en el cargo fue Juan Cáceres Laso de la Vega que ocupó la fiscalía más de veinte años (1777-1797), primero como fiscal único y a partir de 1790 como fiscal civil. También tuvieron fiscalías largas José Ruiz Ubago Busto (1761-1775) -casi catorce años- y Tomás Martínez Galindo (1707-1715) -ocho años-. La fiscalía más corta la desempeñó Cosme García Talón (1716), que falleció a los cuatro meses de haber sido nombrado y Joaquín José Márquez Villalobos (1796-1797), que la ocupó sólo ocho meses.

A lo largo del periodo de nuestro estudio, cuatro fiscales de la Audiencia de Sevilla murieron mientras desempeñaban el cargo: Cosme García Talón (1716), Alonso Rodríguez Castañón (1725), Juan Pérez Vivar (1732) y José Roa Lucas (1800). Desconocemos además el destino de uno de los fiscales cuando abandonó el cargo, Joaquín José Márquez Villalobos, que fue fiscal segundo de la audiencia en el periodo 1796-1797. El resto de los fiscales, tras desempeñar la fiscalía sevillana por un periodo variado, ascendieron a otros puestos de la carrera judicial.

El grupo más significativo siguieron desempeñando plazas de fiscales en tribunales de mayor rango: Chancillerías, Sala de Alcaldes de Casa y Corte de Madrid e incluso diferentes consejos, lo que significa una cierta especialización en el oficio de fiscal dentro de la carrera judicial dieciochista. La mayoría de éstos ascendieron a fiscales de la Chancillería de Valladolid: Tomás Martínez Galindo, Juan Francisco Cuadra Hernández, Felipe Codallos, José Portilla Bustamante y Juan Manuel Cereceda. Sólo uno, Juan Francisco Lerín de Bracamonte, ascendería a fiscal de la Chancillería de Granada ${ }^{60}$. A fiscales de la Sala de Alcaldes de Casa y Corte ascendieron José Ruiz Ubago Busto y Nicolás M. ${ }^{a}$ Sierra. Los que dieron el importante salto a fiscales de consejo son: Juan Francisco Cáceres Laso de la Vega y Juan Pablo Forner, que fueron nombrados fiscales del primer tribunal del reino, el Consejo de Castilla ${ }^{61}$, y José Hevia Noriega, que ascendió a fiscal del Consejo de Guerra ${ }^{62}$. Se sabe que en el ascenso de Forner tuvo mucho que ver la protección que le otorgó Manuel Godoy, del que había sido un servil adulador. Sorprende un poco el caso de Juan Miranda y Oquendo que continuó de fiscal, pero en un tribunal de menor rango que el sevillano, la Audiencia de Galicia, aunque desconocemos las razones por las que aceptó este nombramiento, que de todos modos no fue el último de su brillante carrera ${ }^{63}$.

Otro grupo menos numeroso cambiaron el oficio de fiscal por el de juez. Algunos lo harían dentro de la propia audiencia sevillana, como es el caso de Jerónimo Pesio Mendoza, Pedro D. Contreras Zúñiga ${ }^{64}$ y Francisco Román Meléndez, que obtuvieron

\footnotetext{
${ }^{60}$ Sobre los fiscales de este tribunal véase: GÓMEZ GONZÁLEZ, Inés, La justicia, el gobierno y sus hacedores. La Real Chancillería de Granada en el Antiguo Régimen, Granada, 2003, pp. 41-50.

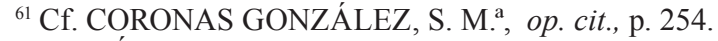

${ }^{62}$ ANDÚJAR CASTILLAO, Francisco, Consejo y consejeros de Guerra en el siglo XVIII, Granada, 1996.

${ }^{63}$ En Galicia permanecería cinco años antes de ascender a fiscal de la Chancillería de Valladolid. Tras 19 años en el este tribunal fue nombrado consejero de Castilla.

${ }^{64}$ En la Cámara de Castilla se apreció su literatura, costumbres y juicio y se le propuso para oidor para otorgarle una comisión y que tomase parte de la visita a los tribunales de México que había em-
} 
nombramientos los tres como jueces civiles del tribunal. A otros el ascenso a juez les obligó a cambiar de residencia. A Francisco Leoz Echalaz el ascenso le permitió volver a su tierra natal, al obtener una plaza de consejero - plaza de navarro- del Consejo Real de Navarra ${ }^{65}$, tribunal equivalente a la audiencia territorial de este reino. En este destino culminaría su carrera. Ramón Navarro Pingarrón ascendió a una plaza de Alcalde de Casa y Corte, José García León y Pizarro a la Presidencia de la Audiencia de Quito ${ }^{66}$ y por último Miguel Gómez García a magistrado de la Audiencia de Castilla la Nueva, en 1825, cuando ya había cambiado la distribución de tribunales propia del Antiguo Régimen.

Para algunos de nuestros fiscales éstos fueron los destinos finales de sus carreras ${ }^{67}$. Otros, en cambio, continuarían ascendiendo a otros puestos dentro del cursus honorum judicial de la época. Los que consiguieron culminar una carrera más brillante, concluyeron sus días en el Consejo de Castilla. Es el caso de Juan Francisco Lerín de Bracamonte, Juan Miranda y Oquendo y Felipe Codallos ${ }^{68}$, nombrados consejeros de Castilla durante el reinado de Carlos III. José Hevia Noriega -que llegaría a ocupar incluso una plaza en la elitista Cámara- y Nicolás M. ${ }^{a}$ Sierra llegarían a consejeros más tarde, ya en el reinado de Fernando VII. Pedro Contreras Zúñiga y José García León Pizarro terminarían como consejeros de Indias ${ }^{69}$. Ramón Navarro Pingarrón, que había sido consejero de Hacienda, terminó su carrera como miembro del tribunal especial de Guerra y Marina durante el trienio constitucional. En otros casos, los ascensos finales les ayudaron a conseguir plazas de oidores, como ocurre con Tomás Martínez Galindo en la Chancillería de Valladolid ${ }^{70}$, Francisco Román Meléndez y José Portilla Bustamante en la Chancillería de Granada.

pezado el inquisidor Pedro Garcerán. Tras su participación en esta visita a los tribunales de Nueva España, sería nombrado consejero de Hacienda togado y de allí ascendería después al Consejo de Indias.

${ }^{65}$ SESÉ ALEGRE, José M., El Consejo Real de Navarra en el siglo XVIII, Pamplona, Eunsa, 1994. Ficha biográfica pp. 237-239.

${ }^{66} \mathrm{Su}$ ficha biográfica en BURKHOLDER, M. A., and CHANDLER, D. S., op. cit., pp. 133-134.

${ }^{67}$ Es el caso de Jerónimo Pesio, que murió siendo oidor de la Audiencia de Sevilla; Francisco Leoz Echalaz, que acabó su carrera como consejero de Navarra, como ya se ha dicho; Juan Francisco Cuadra Hernández, que abandonó la fiscalía de la Chancillería de Valladolid para entrar en un monasterio cartujo; Juan Manuel Cereceda que murió siendo fiscal del crimen en Valladolid; José Ruiz Ubago Busto, que falleció también siendo fiscal de la Sala de Alcaldes de Madrid; de Juan Francisco Cáceres Laso de la Vega y Juan Pablo Forner, que culminaron sus carreras como fiscales del Consejo de Castilla o de Miguel Gómez García, que la culminaría como magistrado en Madrid.

${ }^{68}$ FAYARD, Janine, Los miembros del Consejo de Castilla (1621-1746), Madrid, 1982 y de la misma autora: Los ministros del Consejo Real de Castilla (1621-1788). Informes biográficos, Madrid, 1982. Informe de Lerín de Bracamonte en p. 186 ; el de Miranda y Oquendo en p. 188; el de Felipe Codallos en p. 187.

${ }^{69}$ GARCÍA PÉREZ, R. D., El Consejo de Indias durante los reinados de Carlos III y Carlos IV, Pamplona, 1998 y BURKHOLDER, M. A., Biographical Dictionary of Councilors of Indies, 17171808, New York, Westport, 1984. Ficha biográfica de Contreras Zúñiga en p. 31 y de García León y Pizarro, pp. 46-47.

${ }^{70}$ DOMÍNGUEZ RODRÍGUEZ, Cilia, Los oidores de la Sala de lo civil de la Chancillería castellana, Valladolid, 1997. 


\section{Nobleza e Ilustración}

En general se sitúa a los cargos de la alta administración española en sectores sociales próximos a la pequeña nobleza, o al menos a la hidalguía. En el caso de los fiscales de la Audiencia de Sevilla no hallamos ningún título nobiliario del que fueran titulares ellos mismos. La mayor proximidad a un título nobiliario la encontramos en Felipe Codallos, cuya hija, María Josefa, contrajo matrimonio con Francisco de Valencia, conde de Casavalencia, pero esto no ocurrió durante su estancia en Sevilla, sino posteriormente, en su etapa madrileña, cuando era alcalde de casa y corte o consejero de Castilla, no sabemos bien. Es una prueba del ascenso social de que eran objeto los magistrados de la alta administración española en la época.

Si no encontramos títulos nobiliarios entre nuestros fiscales, si que encontramos al menos algunos hábitos de órdenes militares, lo que suponía dar pruebas inequívocas de antigua y acrisolada nobleza. A la Orden de Santiago, que fue durante la centuria la que gozaba de un mayor prestigio en el exterior y contaba con un mayor número de caballeros, pertenecieron los fiscales Juan Francisco Cuadra Hernández y José Portilla Bustamante ${ }^{71}$, este último era ya caballero con anterioridad a su etapa de fiscal en Sevilla. También fue caballero antes de ser fiscal Alonso Rodríguez Castañón que obtuvo un hábito de Alcántara con 34 años, cuando aún permanecía como colegial en San Ildefonso ${ }^{72}$. Parece que en la consecución del hábito tuvo mucho que ver la influencia de sus tíos, obispos de Zamora, Orense y Calahorra. José García León Pizarro, en cambio, consiguió la merced de un hábito de caballero en la Orden de Carlos III después de su estancia en Sevilla, cuando era presidente de la Audiencia de Quito ${ }^{73}$.

En otros casos tenemos también pruebas indudables de que algunos fiscales pertenecían a familias de acreditada nobleza. Así Francisco Leoz Echalaz era perteneciente a una noble familia navarra. Su padre Francisco de Leoz, había realizado pruebas de nobleza en la Chancillería de Valladolid. Era además sobrino nieto del primer marqués de Zabalegui, Francisco Juániz de Echalaz. Durante toda su vida mantuvo la pretensión de asiento en las Cortes de Navarra, en representación de los palacios de Echarren y Saracóiz, propiedad de su esposa Catalina de Azcona. Cuando consiguió tal reconocimiento acababa de fallecer, por lo que lo sucederían sus hijos en tal privilegio ${ }^{74}$. Por su parte Juan Miranda y Oquendo era hijo de Juan Francisco Miranda Oquendo, regidor perpetuo de Ciudad Rodrigo ${ }^{75}$. La posesión de regidurías perpetuas era, sin duda, una prueba que acreditaba la pertenencia de su linaje por lo menos a la elite oligárquica local. En otros casos, tenemos pruebas de mantener en sus lugares de origen comportamientos sociales que pueden ser

${ }^{71}$ CADENAS Y VICENT, Vicente de, Caballeros de la Orden de Santiago: Siglo XVIII, Madrid, 1977-1996, 9 vols.

${ }^{72}$ CADENAS Y VICENT, Vicente de, Caballeros de la Orden de Alcántara que efectuaron sus pruebas durante el siglo XVIII, Madrid, 1991-1992, 2 vols. Alonso Rodríguez Castañon nº 242, t. I, p. 192.

${ }^{73}$ CADENAS Y VICENT, Vicente de, Extracto de los expedientes de la Orden de Carlos III (17711847), Madrid, 1979-1988, 13 vols. Expediente de José García León y Pizarro nº 977.

${ }^{74}$ SESÉ ALEGRE, José M. ${ }^{\text {a }}$ op. cit., p. 238.

${ }^{75}$ FAYARD, J., Los ministros..., op. cit., p. 188. 
asimilados a comportamientos nobiliarios, como es el ejercicio del mecenazgo cultural, como ocurre con el fiscal Tomás Martínez Galindo, que encargó y costeó en 1730 una imagen de San Miguel para el retablo mayor de la iglesia parroquial de San Miguel de su ciudad natal, Borja, al escultor Simón Lacasa. Por último, también pueden ser asimilados a la pequeña nobleza los fiscales colegiales, dado que en estas fechas los colegios mayores se habían convertido hacía tiempo en un reducto nobiliario.

Cabe preguntarse si nuestros fiscales pueden ser considerados representantes característicos de la Ilustración española. Para dilucidar esta cuestión tenemos como principal fuente el análisis de su producción escrita, en el caso de que la hayan dejado, y la pertenencia a sociedades o academias representativas del espíritu ilustrado. Vamos a centrarnos en primer lugar en la producción intelectual de los fiscales.

El caso más significativo entre el colectivo que estudiamos es el del fiscal Juan Pablo Forner, figura que destaca con luz propia en un colectivo de fiscales con un perfil poco brillante en general. La controvertida figura de Juan Pablo Forner es hay suficientemente conocida y, gracias al estudio de François López, ha pasado de ser considerado un reaccionario ${ }^{76}$, a incluirse en la nómina de los ilustrados.

En los casi seis años de lo que López llama "el purgatorio de Sevilla" 77 (17901796) escribió una parte muy valiosa e interesante de su producción. Destacan sus Nuevas consideraciones sobre la perplejidad de la tortura ${ }^{78}$, disertación jurídica en contra de esta práctica, basada en el examen de la legislación nacional, el derecho romano, la doctrina de los Padres de la Iglesia y los teólogos y el pensamiento de Beccaria, que no llegó a publicarse por falta de autorización -téngase en cuenta que el Colegio de Abogados de Madrid había aprobado el empleo de la tortura en $1777^{79}$. También escribió en Sevilla otra obra que, a juicio de López, es una de las más notables de toda su producción: Discurso sobre el modo de escribir y mejorar la historia de España ${ }^{80}$, donde clama contra la desaparición de la figura del cronista, hace un estudio de la historiografía española y propugna una nueva forma de hacer la historia, que está en la línea de los cambios producidos en la historiografía ilustrada con Voltaire a la cabeza. Obra de madurez que tampoco llegó a publicarse, pese a estar dedicada a la reina, probablemente por las críticas a la Iglesia que contiene. También escribe estos años un Preservativo contra el ateísmo ${ }^{81}$, donde justifica la necesidad de la religión contra la revolución atea. Es una diatriba donde se combate la opinión de Pierre Bayle según la cual una sociedad de ateos practicaría las virtudes civiles y morales como las demás. A juicio de Forner, sin religión no hay virtud y sin ésta no hay sociedad, sino el implacable enfrentamiento de pasiones desenfrenadas. Como ha señalado F. López, se trata de un seco alegato a favor de la religión.

\footnotetext{
${ }^{76}$ MARÍAS, Julián, La España posible en tiempo de Carlos III, Madrid, 1988 (1. a ed. 1963), pp. 54-63

y HERRERO, Javier, Los origenes del pensamiento reaccionario español, Madrid, 1988, pp. 122-124.

${ }^{77}$ LÓPEZ, F., op. cit., pp. 495-555.

${ }^{78}$ Contenida en Obras inéditas, t. $4^{\circ}$. LÓPEZ, F., op. cit., p. 508.

${ }^{79}$ Sobre la polémica suscitada por esta cuestión véase SCANDELLARI, Simonetta, "La polemica sull'abollizione della tortura nella Spagna della seconda metà del secolo XVIII", en Archivio Storico e Giuridico Sardo di Sassari. In memoria di Ginebra Zanetti, Sassari, 1994, pp. 335-372.

${ }^{80}$ Un amplio comentario en LÓPEZ, F., op. cit., pp. 508-531.

${ }^{81}$ Ibídem, pp. 536-538.
} 
También en Sevilla continuaría Forner con su producción poética -anacreónticas, letrillas, poemas de circunstancias-, que se publicarían en diarios de la ciudad y de la vecina Cádiz: Diario histórico y político de Sevilla, Correo de Cádiz, etc., y escribió una obra de teatro: La escuela de la amistad o el filósofo enamorado, en la línea de Moratín, que, a pesar de su escasa calidad, fue estrenada en Cádiz y luego llevada a Madrid, donde se representó en el Teatro de la Cruz, con bastante éxito por cierto ${ }^{82}$. $\mathrm{Y}$ es que Forner fue un gran defensor del teatro, como pone de manifiesto una $\operatorname{Loa}^{83}$ que en defensa del mismo redactó con motivo de la inauguración del Teatro Cómico en 1795 que ponía fin a una de las varias etapas de prohibición del teatro que sufrió la ciudad de Sevilla durante la centuria. En este escrito en verso Forner vindica el teatro y combate la tradicional postura de sus adversarios, afirmando que el teatro no influye en la corrupción de las costumbres, al tiempo que se opone a los predicadores que enseñaban desde el púlpito que era pecado mortal asistir al teatro, acusándoles de presentar como dogmas lo que no son más que sus opiniones personales. La Loa dio origen a una polémica desarrollada en diversos impresos, que ocupó al fiscal en su última etapa sevillana ${ }^{84}$.

En el resto de los fiscales Sevillanos, según el estado de nuestra investigación hasta el momento presente, que sepamos, tan sólo uno de ellos, Tomás Martínez Galindo, publicó una obra que no se derivara de sus obligaciones en el tribunal. La publicó durante su etapa de fiscal en Sevilla (1707-1715) y es de una fecha demasiado temprana para poder ser considerada una obra ilustrada. Se trata de una síntesis donde se realiza una exposición metódica del Derecho civil español, uniendo lo especulativo y lo práctico $^{85}$. Según Peset en esta obra se intentaba simplificar en un solo volumen los fueros, las Partidas y la Recopilación ${ }^{86}$. El resto de los escritos que se conservan de él son impresos de algunas de sus alegaciones fiscales ${ }^{87}$.

Del fiscal Alonso Rodríguez Castañón se conserva impreso un recurso al Consejo de Castilla sobre un pleito particular en el que sus hermanos habían sido condenados

\footnotetext{
${ }^{82}$ Ibídem, pp. 540-541.

${ }^{83}$ Introducción o Loa que se recitó para la apertura del teatro en Sevilla. Año de 1795..., Cádiz, Antonio Murguía, 1796.

${ }^{84}$ Todo este episodio está muy bien descrito en AGUILAR PIÑAL, Francisco, Sevilla y el teatro en el siglo XVIII, Oviedo, Cátedra Feijoo, 1974, pp. 194-199.

${ }^{85}$ La obra fue objeto de dos ediciones que aparecieron con títulos parecidos: Instituta hispanica sive opus singulare institutionum iuris...auctore Doct. D. Thoma Martinez Galindo, Hispali...1713 y Phoenix Iurisprudentiae hispanicae sive Instituta hispana..., auctore D. P. Thoma Martinez Galindo...Hispali, apud Franciscum de Leefdael, 1715.

${ }^{86}$ Citado por MOLAS, Pere, La Audiencia borbónica del reino de Valencia, p. 76.

${ }^{87}$ Breve apuntamiento del fiscal de S. M. sobre que no deve ser restituido a la Iglesia Francisco Delgado, extrahido y preso por el hurto de un copon y Santas Formas del Sagrario de los clérigos menores, y otros diferentes hurtos, Sevilla, 1713 (Citado por LATASSA Y ORTÍN, op. cit., IV, p. 295).
} 
ante la Chancillería de Valladolid ${ }^{88}$, que parecer ser anterior a su etapa de fiscal. También es autor de varias obras manuscritas, que no llegaron a publicarse ${ }^{89}$.

El fiscal Juan de Lerín y Bracamonte durante su etapa de colegial mayor de Santa María de Jesús fue encargado por el colegio, del que entonces era rector, de defender los privilegios de esta corporación, cuya condición de colegio mayor era discutida por algunas instituciones eclesiásticas a la hora de proveer beneficios eclesiásticos ${ }^{90}$. Más tarde, en sus años de fiscal, dio a luz diversos dictámenes, alegatos y censuras, algunas de las cuales se imprimieron. Se conservan varios dictamenes en defensa de la jurisdicción real frente a la injerencia de los tribunales eclesiásticos ${ }^{91}$, así como otros que presentan también un marcado carácter regalísta ${ }^{92}$.

También ha llegado hasta nosotros un informe jurídico del fiscal Felipe Codallos ${ }^{93}$, y una alegación de Juan Francisco Cáceres Laso de la Vega ${ }^{94}$, pero realizadas después

${ }^{88}$ En la vía de recurso al supremo Consejo de Castilla. Por Don Alonso Rodríguez Castañón... En defensa de Don Carlos y Don Diego, sus hermanos, condenados en vista y revista por la Sala del Crimen de la Real Chancillería de Valladolid. En el pleyto que sobre palabras y malos tratamientos ha litigado con los susodichos, Diego Álvarez, todos vecinos del lugar de Lois, Merindad de Baldeburón [s.l., s.i., s.a.].

${ }^{89}$ RAMIREZ DE ARELLANO Y GUTIÉRREZ DE SALAMANCA, C., "Ensayo de un catálogo biográfico-bibliográfico de los escritores que han sido inividuos de las Cuatro Órdenes Militares en España", en Colección de documentos inéditos para la Historia de España, tomo CIX, Madrid, Imp. de José Perales y Martínez, 1894, p. 40.

${ }^{90}$ Compendio apologético y jurídico de los títulos y privilegios en que se funda la graduación del Collegio Mayor de Sevilla, con omnímoda igualdad a los demás Collegios Mayores. Citado por Aguilar Piñal, F., La Universidad de Sevilla ..., p. 444. El Memorial de Lerín de Bracamonte: Señor, el Doctor Juan Balthasar de Lerín Bracamonte, Colegial: Rector... del Colegio Mayor de Santa M. ${ }^{a}$ de Jesús... de Sevilla ... promueve en la Real Piedad de V. Mag. la sentida quexa de la notoria injusticia, que a dicho su colegio se hace disputándole en algunas Santas Iglesias de Castilla el relevante honor de la Mayoría, que por derecho compete a su preeminente graduación [s.l., s.i., s.a.].

${ }^{91}$ Dictamen que un buen hombre dio, que ha impresso y repartido el Doctor Don Juan Lerín de Bracamonte, Fiscal de la Real Audiencia de Sevilla, en que pretende se dé auto de legos en los eclesiásticos, de que está conociendo el Dr. D. Pedro Curiel, canónigo de la Santa Iglesia de dicha ciudad..., Sevilla, [s.i.] [1734] y Defensa de la jurisdicción real. Por... Juan Lerín de Bracamonte... Fiscal de Su Majestad en Sevilla, en el recurso de fuerza, que ha traido sobre que se declare la que en conocer i proceder hace, i comete el juez de la Santa Iglesia de este Arzobispado, en el pleito, i causa criminal, en que procede a declarar incursos en las censuras de la Bula de la Cena i de el Canon, a los ministros de una Rona, por haver aprissionado i herido a don Juan Francisco de Mercado, clérigo de tonsura no dispensado, [s.l., s.i., s.a.].

${ }^{92}$ Por la Suprema Potestad y Regalías de Su Mag. en el establecimiento de estancos, prohibición de comercios y concesión de monopolios, en el régimen temporal de sus dominios, sin excepciones de los eclesiásticos regulares y seculares. Escribe el Dr. D..., Fiscal de S. M. en la Real Audiencia de Sevilla, [s.l., s.i., s.a.].

${ }^{93}$ Informe juridico en el recurso de fuerza intentado en esta Real Chancillería sobre no haver otorgado el provisor de esta ciudad a la parte del jurisdicción real libremente las apelaciones en los autos de el clericato y fuero que se atribuye Vicente Velarde, reo presso y condenado a muerte por la sala del crimen, escrivíalo... Phelipe Codallos... fiscal. En Valladolid, en la oficina de Fernando del Villar [s.a.].

${ }^{94}$ Alegación en derecho en defensa de la regalia de S. M. de que hace mención y específica el Señor Fiscal D. Francisco de Cáceres Laso de la Vega en el pleyto que sigue sobre retención de unas letras circunscriptivas de la signatura de la Gracia de Roma..., Madrid, Imprenta Real, 1800. 
de haber abandonado ambos Sevilla, durante su etapa de fiscal en la Chancillería de Valladolid y de fiscal del Consejo de Castilla respectivamente.

Por último, del fiscal Nicolás M. Sierra se conserva alguna disertación latina de su época de estudiante ${ }^{95}$, pero nada relativo a su labor en la administración.

Otro indicador de Ilustración puede ser la pertenencia a Academias o a Sociedades Económicas de Amigos del País. Entre los fiscales sevillanos sólo hemos acreditado la presencia de uno de ellos en academias de Madrid, Alonso Rodríguez Castañón, que fue académico de la Real Academia española desde su nombramiento en 1717 hasta su muerte en 1725. Sí sabemos que algunos de ellos fueron miembros y participaron activamente en la Real Academia Sevillana de Buenas Letras, organismo fundado en 1751 que tenía como principal objetivo el desarrollo de los estudios históricos, pero que abrió sus disertaciones a campos como la arqueología, numismática, lingüística, literatura y geografía. Este organismo, que gozó de la protección real, contó entre sus miembros con un elenco importante de magistrados de la Audiencia ${ }^{96}$.

Por lo que se refiere a los fiscales, fueron miembros de pleno derecho de esta academia Juan Pablo Forner y Nicolás M. ${ }^{a}$ Sierra. Forner entró en la academia cuando llevaba aproximadamente un año de fiscal en la Audiencia y lo hizo a instancias de la propia institución que le ofreció una plaza de académico honorario ${ }^{97}$. Ingresó como académico honorario el 3 de junio de 1791, leyendo un discurso en el que trataba de la Importancia de la historia para la jurisprudencia. Participó en las labores académicas muy activamente, actuando como juez en certámenes convocados por ella y el 14 de septiembre ascendió a numerario. En 1793 disertó en la Academia sobre las Causas del mal gusto en la literatura ${ }^{98}$.

También fue muy grande la implicación con la Academia del fiscal Nicolás M. ${ }^{a}$ Sierra, académico de número que el 24 de abril de 1805 sería nombrado director. Sería el último director de la Academia sevillana en esta primera época de su historia, pues al renunciar al cargo, por haber sido nombrado fiscal del Consejo de Castilla, la corporación decidió de forma unánime dejar el cargo vacante y pasar a ser regida por el académico más antiguo ${ }^{99}$. También fue académico, pero en este caso de carácter honorario, el fiscal Juan Francisco Cáceres Laso de la Vega, aunque no tenemos noticias de su actividad en la corporación ${ }^{100}$.

También se implicaron bastante los magistrados de la Audiencia en la Económica de la ciudad. La Real Sociedad Patriótica de la ciudad y reino de Sevilla, fundada

\footnotetext{
${ }^{95}$ Rethoricae propositionis A. Ioanne Oviedo Sendin de Ulloa defensandae quas interpretatus $M$. T. Cicerones orationem pro lege manilia publico certamini offerebat Nicolaus Maria de Sierra, Salmanticae, officina Andreae Garcia Rico, s.a. (Se trata de una disertación fechada en 1789).

${ }^{96}$ AGUILAR PIÑAL, Francisco, La Real Academia Sevillana de Buenas Letras en el siglo XVIII, Madrid, CSIC, 1966.

97 "La Academia determinó en atención al público mérito literario y personal con que se ha condecorado por sus producciones al señor don Juan Pablo Forner, Fiscal de la Real Audiencia de Sevilla, se le ofreciese la plaza da académico, la cual en aquel mismo día la aceptó y tomó posesión" (Ibiden, pp. 21-22).

${ }^{98}$ Ibídem, pp. 265-272

${ }^{99}$ Ibidem, pp. 131 y 182.

${ }^{100}$ Ibídem, p. 317
} 
en 1775 contó entre sus oficiales algunos de los magistrados más brillantes de la Audiencia. De los fiscales, sólo sabemos que formó parte Juan Pablo Forner, que fue director de la misma en el período 1796-97101. Aunque no está suficientemente estudiada la actividad de la Económica en estos años, se conoce la implicación de Forner en diferentes proyectos que llevaba a cabo en estos momentos la Sociedad, que iban desde a la preocupación por las escuelas públicas, a equipar laboratorios de química, a sacar provecho de las tierras sin cultivar o a fundar montes de piedad y asilos para pobres ${ }^{102}$. Se conserva algún manuscrito de sus discursos pronunciados ante las juntas de la Sociedad ${ }^{103}$ y un interesante impreso de un discurso titulado Amor a la Patria ${ }^{104}$, donde, como un auténtico ilustrado, defiende al régimen monárquico como el único capaz de regenerar el país. Un escrito muy interesante desde el punto de vista ideológico, a juicio de François López, porque en él se esboza una teoría del nacionalismo que se adelanta a la formulada en el siglo XIX y que servirá de inspiración a los conservadores de esta etapa.

En 1793 se creó en la ciudad de Sevilla la Academia de Letras Humanas, fundada por un grupo de teólogos con Félix José Reinoso a la cabeza, en la que pronto se incluirían personajes tan interesantes como Alberto Lista y José M. Blanco White. Sabemos que Forner fue requerido por estos jóvenes para que participara como censor y juez imparcial en sus certámenes poéticos ${ }^{105}$, aunque no parece que este caso su vinculación con esta corporación fuera más allá.

También en los años finales del siglo XVIII se creó una Academia de Derecho en Sevilla. En 1790 fueron aprobadas sus Ordenanzas, pero apenas se poseen algunas noticias sueltas de ella. El fiscal Forner formó parte de la misma y es muy probable que lo hicieran también otros magistrados de la Audiencia ${ }^{106}$.

Más allá de sus escritos o de la pertenencia a asociaciones es poco lo que podemos señalar acerca de la ideología de nuestros fiscales. No obstante tenemos algunos otros datos que proporcionan información sobre el posicionamiento político de algunos de ellos. Según la información de la Secretaría de Estado en vísperas de la reforma de los colegios mayores, Juan Miranda y Oquendo, que en estos momentos era fiscal de la Chancillería de Valladolid, se situaba en el partido antijesuítico ${ }^{107}$. También

${ }^{101}$ DEMERSON, Paula y Jorge y AGUILAR PIÑAL, Francisco, Las Sociedades Económicas de Amigos del País en el siglo XVIII. Guía del investigador, San Sebastián, 1974, p. 284.

${ }^{102}$ Todas estas actividades "de un auténtico ilustrado" las enumera F. López basándose en el Elogio pronunciado por Joaquín María Sotelo, con motivo de su entrada en la Real Academia de Derecho de la Corte (op. cit., p. 532).

${ }^{103}$ Archivo de la Sociedad Económica Matritense, leg. 124, exp. 14 (1796)

${ }^{104}$ FORNER, Juan Pablo, Amor a la Patria. Discurso que en la Junta general pública que celebró la Real Sociedad Económica de Sevilla el día 23 de noviembre de 1794 leyó D. .... Fiscal del Crimen de la Real Audiencia y Director de la Sociedad. Publicado de acuerdo y a expensas de ésta, Sevilla, Hidalgo y González de la Bonilla, [1794]. Un comentario de la misma en LÓPEZ, F., op. cit., pp. 532-536.

${ }^{105}$ AGUILAR PIÑAL, Francisco, "La Academia de Letras Humanas (1793-1801)", en Temas Sevillanos. Segunda Serie, Sevilla, Universidad de Sevilla, 1988, pp. 57-77.

${ }^{106}$ Francisco Aguilar Piñal se refiere a ella como academia de Derecho real, Historia de Sevilla. Siglo XVIII, Sevilla, 1982, p. 359. Por su parte François López habla de una Academia de Derecho canónico e historia eclesiástica, op. cit., p. 532.

${ }^{107}$ OLAECHEA, Rafael, "Política anticolegialista del reinado de Carlos III", en II Simposio sobre 
Felipe Codallos puede ser considerado antijesuita, pues fue miembro del Consejo extraordinario que decidiría sobre la expulsión de la Compañía y posteriormente sería encargado de la administración de las temporalidades del Colegio Imperial de Madrid $^{108}$. Por último, también puede ser tomada como muestra de ideología ilustrada la contundente actuación del fiscal José García León y Pizarro contra la sátira Vida de don Guindo Cerezo, que corrió manuscrita por Sevilla en 1776, conteniendo una cruel crítica contra Olavide. El fiscal la calificó de "infame libelo" y mandó recoger y quemar los ejemplares existentes y buscar a su autor. Aguilar Piñal piensa que debió actuar aconsejado por Jovellanos y Aguirre, alcaldes del crimen de la Audiencia y amigos ambos del asistente ${ }^{109}$, pero esta circunstancia no quitaría valor a su actuación.

el P. Feijoo y su siglo, Oviedo, Universidad-Centro Estudios S. XVIII-Cátedra Feijoo, 1983, vol. II, pp. 207-246.

${ }^{108}$ AGS, Gracia y Justicia, leg. 372.

${ }^{109}$ AGUILAR PIÑAL, Francisco, La Sevilla de Olavide, 1767-1778, Sevilla, 1966, p. 215. 
FISCALES DE LA AUDIENCIA DE SEVILLA EN EL SIGLO XVIII

\begin{tabular}{|c|c|c|c|c|c|c|}
\hline & COL. & CAT. & ENTRADA & ANTERIOR & ASCENSO & TÉRMINO \\
\hline J. Pesio Mendoza (1699-1707) & & & & & O.A.SE. & O.A.SE. \\
\hline T. Martínez Galindo (1707-1715) & & & & Abogado & F.CH.VA. & O.CH.VA. \\
\hline C. García Talón (1716-1716) & & & F.A.VL. & A.C.C. & m.c. & \\
\hline P. Contreras Zúñiga (1716-1720) & $\mathrm{AR}$ & SA & F.A.SE. & Cat. Salam. & O.A.SE. & C.I. \\
\hline F. Leoz Echalaz (1720-1724) & SB & SA & F.A.SE. & Cat. Salam. & O.C.NA. & O.C.NA. \\
\hline A. Rodríguez Castañón (1724-1725) & SI & $\mathrm{AL}$ & F.A.SE. & Cat. Alcalá & m.c. & \\
\hline F. Román Meléndez (1725-1729) & & & F.A.CA. & J.A.CA. & O.A.SE. & O.CH.GR. \\
\hline J. Pérez Vivar (1729-1732) & & & & Correg. Huete & m.c. & \\
\hline J. F. Lerin Bracamonte (1732-1738) & $\mathrm{JE}$ & $\mathrm{SE}$ & F.A.SE. & Cat. Sevilla & F.CH.GR. & C.C. \\
\hline J. Miranda Oquendo (1738-1743) & & & F.A.SE. & Cat. Salam. & F.A.GA. & C.C. \\
\hline J. F. Cuadra Hernández (1739-1744) & SI & & F.A.SE. & & F.CH.VA. & cartujo \\
\hline F. Codallos (1744-1750) & & $\mathrm{HU}$ & F.A.SE. & Cat. Huesca & F.CH.VA. & C.C. \\
\hline J. Portilla Bustamante (1750-1755) & & & F.A.SE. & & F.CH.VA. & O.CH.GR. \\
\hline J. M. Cereceda (1755-1761) & $\mathrm{SC}$ & & F.A.SE. & Cat. Valladolid & F.CH.VA. & F.CH.VA. \\
\hline J. Ruiz Ubago Busto (1761-1775) & $\mathrm{SC}$ & VA & F.A.SE. & Cat. Valladolid & F.S.A.C.C. & F.S.A.C.C. \\
\hline J. García León Pizarro (1775-1776) & & VA & & Correg. Baeza & P.A. Quito & C.C.I. \\
\hline J. Cáceres Laso Vega (1777-1797) & & & F.A.SE. & & F.C.C. & F.C.C. \\
\hline Juan Pablo Forner (1790-1796) & & & F.A.SE. & & F.C.C. & F.C.C. \\
\hline J.J. Márquez Villalobos (1796-1797) & SB & & F.A.SE. & Rector SB & & \\
\hline J. Roa Lucas (1797-99) (1799-00) & & & F.A.SE. & & m.c. & \\
\hline J. Hevia Noriega (1800-1813) & & & F.A.SE. & Abogado & F.C.GU. & C.C.C. \\
\hline J. A. Fernández Soler (1800-1802) & & & Alc. M. Cazorla & Alc.M.S.Sevilla & m.c. & \\
\hline R. Navarro Pingarrón (1802-1802) & & & Alc. M. Lezuza & Correg. Baeza & A.C.C. & Tr. G. M. \\
\hline N. M. Sierra (1802-1807) & SB & & F.A.SE. & Colegial & F.S.A.C.C. & C.C.R. \\
\hline M. Gómez García (1807-1825) & & & & & M.A.CN. & \\
\hline
\end{tabular}

